\title{
Symptoms of Adopted Children Presenting to a Large Mental Health Clinic*
}

\author{
Carol C. Austad, MD \\ University of Michigan \\ Tillmon L. Simmons, MD \\ Medical University of South Carolina
}

\begin{abstract}
The intake records of a selected sample of children adopted in early infancy are reviewed and their presenting symptoms categorized. A majority of the children's symptoms fell into the first 5 of 15 categories: Oppositional Behavior, Aggressive Behavior, Anti-social Acting Out, Academic Problems and Problems with Peers. While these symptoms are not uncommon in non-adoptive clinic cases, the authors note an emphasis on the adoptive parents' disappointment and accusatory attitude toward these children as well as a high incidence of symptoms indicative of interpersonal difficulties and problems in developing solid parental attachments and self-control.
\end{abstract}

Adopted children are said to present to mental health clinics more often than their non-adopted peers $[1,2,3,8]$. Some authors imply that not only are adopted children referred more frequently but that their symptoms are related to the fact of being adopted $[4,5]$. In the process of examining these implications the investigators reviewed the records of over 200 adopted children who were brought to our outpatient department for evaluation during the 10 year period from 19641974. Because the investigators noted many similar complaints about the adopted children evaluated, a study was undertaken to determine if any commonalities existed in the types of symptoms and complaints that brought these children to our clinic.

In this paper we will discuss the presenting symptoms or as was of-

*University of Michigan, Youth Services, Children's Psychiatry Hospital, Adoption Study Project, Ann Arbor, Michigan.

Dr. Austad is a Clinical Instructor in Child Psychiatry, University of Michigan, Department of Psychiatry, Youth Services, Ann Arbor MI 48109. Dr. Simmons is Assistant Professor, Department of Psychiatry, Medical University of South Carolina, Charleston, SC. Reprint requests should be addressed to Dr. Austad. 
ten noted, the presenting parental complaints of a selected group of adopted cases. We chose a selected group of these cases in order to reduce as much as possible the causal factors in symptom production during childhood to the single fact of adoption. Offord et al. [7] report findings suggesting the nature and severity of symptoms is related to the child's age at adoption. (Specifically he concluded that children adopted after 6 months of age were referred most frequently for anti-social symptomotology.) We feel the effects of changes in caretakers early in life alone could account for Offord's findings. Therefore, to avoid the fact of multiple placement or caretakers prior to adoption, we decided to include in our sample only those children adopted early in infancy, i.e., within the first 3 months of life. To further purify our sample we excluded all those cases in which there was neurological evidence of organic brain disease, minimal brain dysfunction, divorce of the adoptive parents prior to the onset of symptoms, death of an adoptive parent, step-parents, disruptive surgeries or concealed kinship adoption. Our final sample of 33 cases we refer to as "early clean" adoptions. The term "early" indicates adoption within the first 3 months of life thus minimizing the psychological effects of broken relationships with caretakers other than the adoptive parents. The term "clean" indicates that we included in our sample only those cases in which situations had not occurred which we knew could cause psychological problems and symptoms in their own right. The children in our sample ranged in age from 2 years to 16 years though most were latency-aged youngsters. Out of the 33 cases, 23 were male and 10 female.

In reviewing the cases we found that because many of the children had undergone previous school and agency evaluations, the presenting symptoms were often stated in terms of a diagnosis or an interpretation of a problem rather than the original symptorns. To minimize this difficulty we decided to include as presenting symptoms only descriptions of the child's behavior as reported by the parents and educators. We found these presenting symptoms to constitute a long list, many of which appeared to lend themselves to categorization. (The mean number of symptoms per child was 4.7 ; the median was 5 and the range of symptoms per child was 1 to 9.) In order to categorize the symptoms we distributed protocols to each member of our multidisciplinary study team and asked them to group the presenting symptoms into categories. Out of this process emerged the 15 categories represented in Table I into which all raters consistently placed all presenting symptoms. It is important to note that over 60 percent of the individual symptoms are contained in the first 5 cate- 
TABLE I

CATEGORIES OF PRESENTING SYMPTOMS OF ADOPTED CHILDREN

Symptom Type

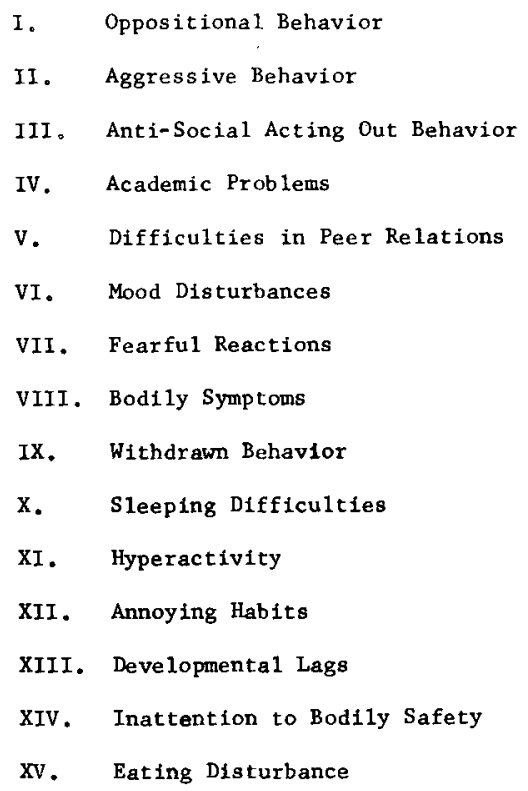

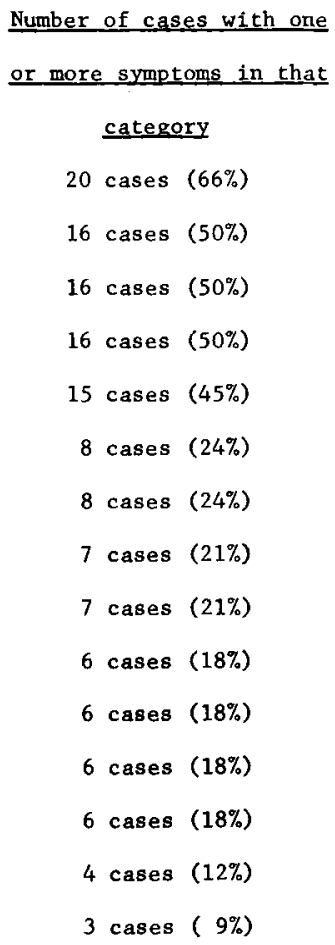

gories. We will first discuss the content of these categories containing the greatest number of symptoms.

The largest category was that of "Oppositional Behavior." The symptoms included in this group were parent or teacher complaints of unmanageability, resisting discipline, stubbornness and temper tantrums. Sixty-six percent of the cases studied had symptoms which fell into this category. Even though children with symptoms in this category presented with a wide range of oppositional behaviors, we noted 3 relevant trends in symptom presentation.

First, only $50 \%$ of the time were parents and teachers in agreement that the child was oppositional. Some examples include one 10-yearold girl referred at the school's insistence for unhappiness and stubborn behavior, who was likewise troublesome to parents for "being 
hard to get along with" and having temper tantrums when frustrated. Another 11-year-old boy was described by both his parents and school officials as being defiant, insolent, bossy and hostile.

As noted, frequently parents and teachers did not agree that the child was oppositional. For example in spite of one 10-year-old's sullen, defiant behavior at home, he was reported by the school teacher to be doing satisfactorily in all areas of social adjustment. Another 11-year-old boy was so destructive at home that his parents arrived at the clinic fearful of returning home with their son, although written reports from his teachers indicated that he was no particular problem in school.

Second, the only two youngsters of toddler age (2 years 2 months and 2 years 10 months were brought, primarily because of each mother's concern that her adopted child was abnormal because he was having temper tantrums and was negative to discipline. It is possible that the mothers misperceived normal, 2-year-old behaviors actually appropriate to the child's developmental stage.

Third, of the 4 cases of children over 13 years of age with oppositional symptoms, 3 (all boys) were finally brought for evaluation because of openly aggressive, disobedient behavior bordering on delinquency. In fact 2 of these 3 had been expelled from their schools, 1 interestingly had already been sent away as troublesome and was expelled from a boarding school. The fourth teenager, the only girl in the group, was described as having a "hatred complex" and arguing with her parents.

The next category, "Aggressive Behavior," included only cases in which there were complaints that a child was openly, physically aggressive toward others. These children were most frequently indicted for spontaneous attacks on peers and siblings. These attacks involved biting, kicking or throwing objects. Fifty percent of case histories studied had symptoms in this category. There was no correlation between these complaints and the age of the child, as there was a wide range of ages represented. There was however a striking preponderance of boys in this sample as only 1 of the 16 cases with symptoms of this type was a female. Even in this case the child's aggressive behavior was limited to fights with her sister. Again a trend was noted in that educators did not consider the child as an aggressive problem nearly as frequently as the parents. In 2 of the cases school personnel were frankly surprised that the child was referred.

The category of "Anti-social Acting Out Behavior" including lying, stealing, running away, drug use and sexual acting out. Fifty percent of the cases studied have symptoms in this group. There was no cor- 
relation between the symptoms and the child's age. Relative to the number of girls in this "early clean" sample, a striking proportion presented with symptoms classified as anti-social acting out. In fact, 6 out of the total of 10 girls were brought for these complaints. It is likely that these behaviors may be an expression of aggression in some girls, paralleling the more open aggression of the boys. This tends to follow our experience with a large general outpatient population in that girls were seldom brought with a complaint of openly aggressive behavior, but more often did get referred for drug use, sexual acting out and running away.

The next category, "Academic Problems," included actual academic difficulties separate from all other problems children may have in school. Fifty percent of the cases had symptoms in this category. In only half of these did educators and parents agree that the child was not doing as well academically as he should be able to by endowment. In more than a quarter of the cases parents were concerned that their child should be doing better but the teachers did not note this to be so in the reports to us. For example, in the case of one 10-year-old girl her teacher found her academically quite satisfactory for her age while her mother had been seeking to prove that the child had some sort of organic brain problem and needed special educational placement. In an other case a boy was referred at 9 years of age because his teacher felt that he was working up to his somewhat limited potential but his parents were worried that his relatively low grades were not related to endowment but were in fact due to emotional problems. In a few cases the teachers felt that the child was underachieving but the parents did not seem concerned. In these cases educators noted that the children did not complete their work or that their performance varied from day to day.

The last large category of presenting symptoms is that of "Difficulties in Peer Relationships" and included only children listed as specifically having difficulties in initiating or maintaining friendships. Forty-five percent of cases studied had symptoms in this category. Strikingly, all but 2 of these children had aggressive problems of one sort or another which presumably discouraged peers. In addition, several children were noted to be unattractive to peers because they boasted, or were bossy; perhaps in an effort to befriend other children. Two children were avoided specifically because they teased and taunted their playmates. Three children were described simply as avoiding or shy of friends, perhaps "loners" of a sort.

As stated previously $60 \%$ of the presenting symptoms fell into the first 5 categories which we have just discussed. The remaining $40 \%$ 
fall into the other 10 categories. The number of cases in these categories was so small and the symptoms so variable that only a few relevant correlations could be found. We will note briefly observations from 2 categories: (1) In "Mood Disturbances" we included complaints from parents and teachers that children were sullen, unhappy, irritable, tearful, under and over demonstrative of affection. The children most often brought with these complaints were pubertal girls. Universally, their adults complained that these girls were tearful and moody implying that the girls were overly sensitive. The few boys in this category were described as sullen, angry and unhappy. (2) The category of "Withdrawn Behavior" included those children who were described as overly passive, shy or seclusive. Twenty-one percent of the children had symptoms in this category and ranged in age from 10 to 13 years.

It is of interest to note that in the two categories just described the children most often brought were pre-pubertal or pubertal. Students of human development agree that children of this age are in fact "moody" due to developmental and physical pressures. It is possible that again the adoptive parents overreacted to a difficult but normal developmental phase.

\section{Discussion}

In the preceeding pages, we have reviewed the presenting symptoms of a selected group of 33 adopted children (those who appear to have had no overwhelming developmental interferences that could alone account for emotional disturbance). We discovered that these adopted children were brought with such a wide variety of complaints and symptomatic behaviors that no striking trend can be immediately identified that would distinguish these children from non-adoptive children brought to our clinic for evaluation.

In spite of lack of dramatic differences in presenting symptoms, there did seem to be a subtle difference in the way symptoms were described by educators and parents. For example, the parents in this sample seemed not so often concerned about their child's emotional well-being as they were upset that their adoptive children did not conform to expectations. It is our observation that in this sample, symptoms motivating parental referral were related to disappointment in their adopted child; parents many times could be imagined as antagonistic and accusing from the intake data. It seems as though the parents were often hurt or angry that their child behaved badly in spite of their considerable efforts. While we do not have a matched 
control sample of non-adopted children as yet, our impression is that many of these parents experienced less guilt in complaining about their child's perceived inadequacies or bad behaviors than parents bringing in their biological children who have emotional disturbances. This impression is supported by observing the major symptom categories: Oppositional Behavior, Aggressive Behavior, Anti-Social Acting Out Behavior, Academic Problems and Difficulties in Peer Relationships. Sixty percent of all the symptoms belong to these categories, all of which include behaviors of a negative or disappointing type much as noted by Offord [7] who studied children adopted at a later age. In addition, there was evidence of a tendency to interpret phase appropriate behavior as bad behavior on the child's part; such as in the case of the 2-year-olds described as stubborn and resistent and in the case of the pre-pubertal children who displayed "moody" behaviors. While on the one hand adoptive parents may be sensitive to normal but difficult developmental phases, it is quite likely that in certain developmental stages in the adopted child's life difficult behavior is magnified and, in fact, more worrisome than in children who are not dealing with the psychic fact of adoption.

It should also be noted that these same 5 major categories, in general, include symptoms of interpersonal difficulties, perhaps not reflecting so much the difficult fantasy life of an adopted child, but more indicative of vulnerabilities in early parent-child interpersonal attachments and interpersonal comfort. In the words of an 11-yearold adopted boy quoted by Kirk [4] :

The child who is born into his family is like a board that is nailed down from the start. But the adopted child, him, the parents have to nail down, otherwise he's like a loose board in mid-air. (Preface viii)

In summary we can only conclude that surface behavior and symptoms bringing the adopted child to treatment can be misleading and obscure the part adoption plays in the psychic life of a child and his adoptive parents and in the creation of the disturbance. We note that even children adopted very early in life may tend to present behavioral problems of non-neurotic nature perhaps indicative that the fact of adoption can create ongoing difficulties in interpersonal relationships and firm attachments regardless of the age of the child at the time of adoption. It seems likely that in some families adoption presents a significant interference to parent-child attachment long before the child understands his adoption and in spite of adoption very early in infancy. 


\section{References}

1. Schechter MD: Observations on adopted children. Arch Gen Psychiatry 3:21$32,1960$.

2. Simon NM, Senturia AG: Adoption and psychiatric illness. Am J Psychiatry 122:858-867, 1966.

3. Goodman JD, Silberstein RM, Mandell W: Adopted children brought to child psychiatric clinic. Arch Gen Psychiatry 9:451-456, 1963.

4. Kirk HD: Shared Fate: A Theory of Adoption and Mental Health. New York: New York Free Press, 1964.

5. Rutter M, Hersov L: Child Psychiatry-Modern Approaches. Blackwell Scientific Publications.

6. Solnit A: A psychoanalytic view of the adoptive mother, reference to in symposium representation by Schecter Fall Meetings. Am Psychoanal Assoc, 1966.

7. Offord DR, Hershey PA, Aponte JF, Cross LA: Presenting symptomatology of adopted children. Arch Gen Psychiatry 20:110-116, 1969.

8. Clothier F: The psychology of the adopted child. Mental Hygiene 27:222$230,1943$. 